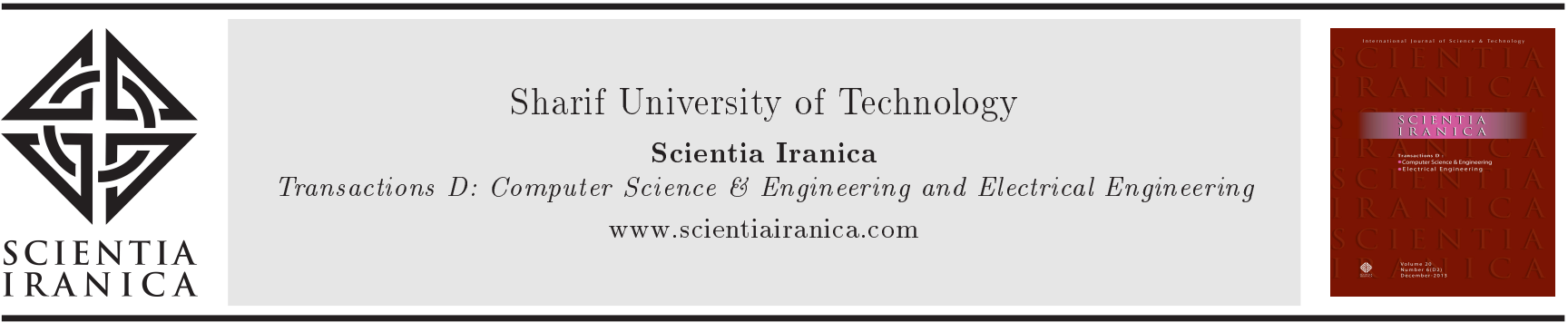

\title{
Effects of leakage inductance on the input current of double-star diode rectifier with active inter-phase reactor
}

\author{
J. Wang and S. Yang* \\ School of Electrical Engineering and Automation, Harbin Institute of Technology, Harbin, China.
}

Received 19 September 2015; received in revised form 5 May 2016; accepted 4 July 2016

\author{
KEYWORDS \\ Double-star diode \\ rectifier; \\ Leakage inductance; \\ Input current THD; \\ Active inter-phase \\ reactor; \\ The input current lag \\ angle.
}

\begin{abstract}
An Active Inter-Phase Reactor (AIPR) is often employed to inject triangle current to improve the input current quality of double-star diode rectifier. Due to the existing leakage inductance of transformer, the input current harmonics suppression ability of the injected triangle current would be weakened. In this paper, the current commutation process of the double-star diode rectifier with AIPR is analyzed initially. Then, according to the relation between the input current and output current of the double-star transformer, the relation between the leakage inductance and the input line current of double-star diode rectifier with AIPR is established. Such factors like the input current THD, the input current lag angle, and power factor of the double-star diode rectifier with AIPR as well as their relations with the leakage inductance are also obtained. The theoretical analysis demonstrates that leakage inductance increases the input current THD and lag angle. It indicates that leakage inductance decreases the displacement factor and power factor. To ensure the input current THD is less than $5 \%$ and the power factor is more than 0.998 , the leakage inductance factor, $K_{L S}$, should be less than 0.22 . Simulation results verify the theoretical analysis.

(C) 2017 Sharif University of Technology. All rights reserved.
\end{abstract}

\section{Introduction}

Diode rectifiers are widely used due to their ruggedness, simplicity, and low price $[1,2]$. However, they draw distorted currents from the ac supply and do not meet the requirements of the harmonics standard $[3,4]$. Therefore, researchers have explored a variety of methods to reduce the input line current distortion of diode rectifiers in recent decades [5-26]. Compared with other harmonic reduction methods, because of the small kilo-

\footnotetext{
*. Corresponding author. Tel.: +86045186413301; Fax: +86 13804506002

E-mail addresses: wjfyj550@126.com (J. Wang); syyang@hit.edu (S. Yang)
}

Volt Ampere (kVA) rating of auxiliary current injection circuit and excellent harmonic reduction ability, the method of active harmonic reduction at dc side is suitable for high power applications and has drawn more and more attention [16-26].

In [18], the concept of Active Inter-Phase Reactor (AIPR) was proposed in 12-pulse diode rectifier. The low-kVA $(2 \%$ Po) active auxiliary circuit injects a triangular current into the extra winding of the AIPR. The resulting system draws near sinusoidal input currents with less than $1 \%$ THD. In [19], the method to reduce the ac-side harmonics of series-connected 12 pulse diode rectifier utilizing dc-side active auxiliary circuit formed by two buck-and-boost converters is presented. The auxiliary circuit is placed parallel to each six-pulse rectifier bridge to inject current and shape the rectifier output current. The resulting THD 
is below $5 \%$ and the kilovolt ampere rating of auxiliary circuit is less than $15 \%$ Po. In [20], an AIPR scheme to achieve near sinusoidal input line currents for a 24-pulse converter is proposed. The proposed AIPT scheme consists of three IPTs and a current-controlled inverter with rating required to be only $1.16 \%$ of the system power rating. In [21], a double-star diode rectifier with an auxiliary PWM rectifier is also presented. It draws near sinusoidal utility line currents with less than 5\% THD. Besides the introduced dc-side active current injection schemes, the authors in [22-26] also proposed diode rectifiers with an auxiliary current injection circuit at dc-side.

However, those dc-side active current injection schemes were not concerned with the effects of leakage inductance of transformer. In the high power applications, the effects of the leakage inductance of transformer are more serious and should not be ignored. In order to clarify the effects of leakage inductance of transformer on the input current, this paper sets the double-star diode rectifier with AIPR as an example and the effects of leakage inductance of transformer on the input current are analyzed in depth. Due to the essence of the diode rectifiers, the same active current injection reduction method is used; the analysis of the effects of leakage inductance of transformer on the input current can be extended to other diode rectifiers with active current injection circuit.

\section{Theoretical analysis}

2.1. The double-star diode rectifier with AIPR Figure 1 shows the double-star diode rectifier with AIPR. Compared with the conventional double-star diode rectifier, the Inter-Phase Reactor (IPR) is replaced by the AIPR. The AIPR consists of the specific IPR with an additional secondary winding and a smallkVA active auxiliary circuit. The active auxiliary
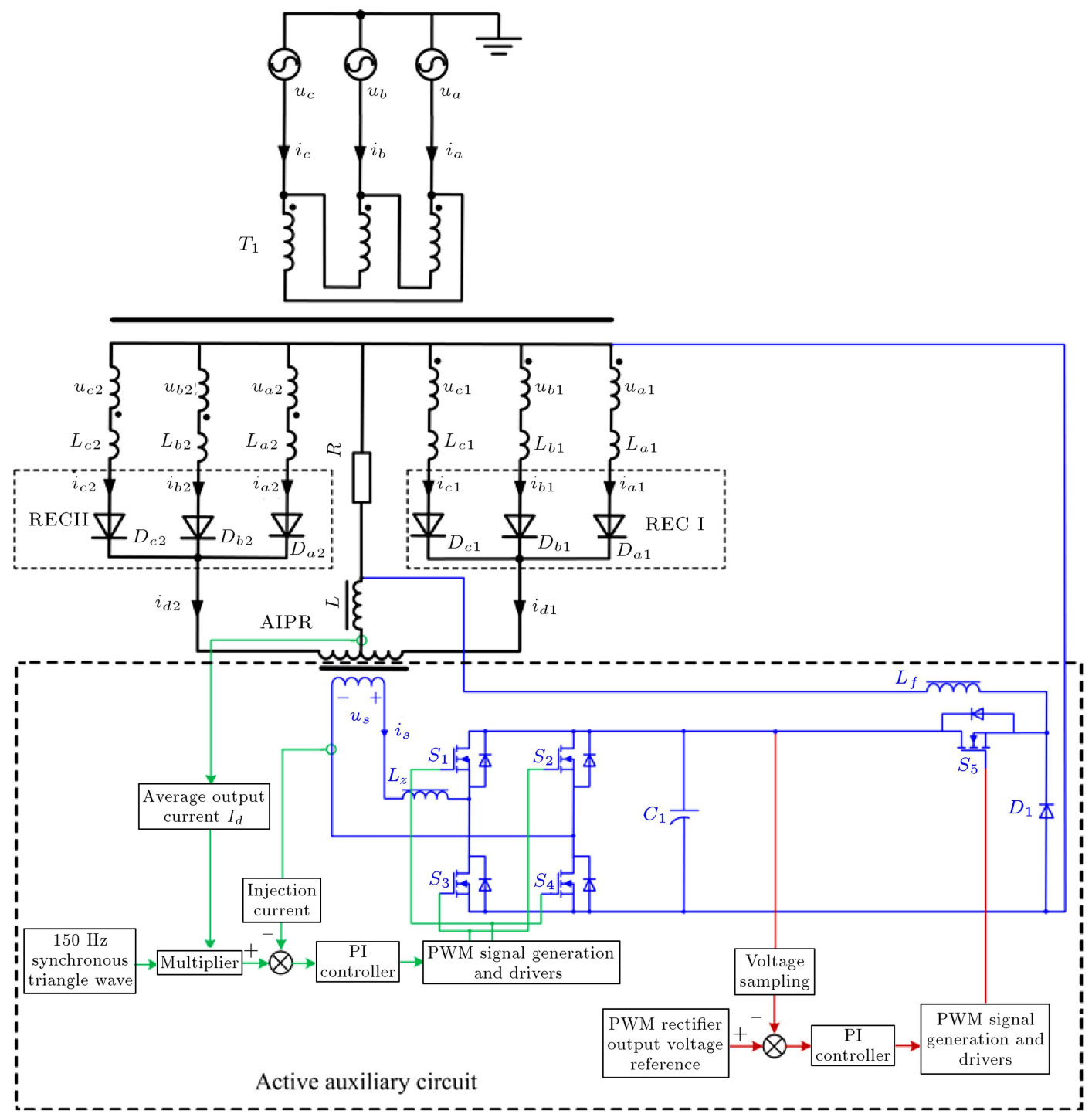

Figure 1. The double-star diode rectifier with AIPR. 
circuit consists of the auxiliary PWM rectifier and the buck conventer. The auxiliary PWM rectifier injects the triangle current into the double-star diode rectifier to shape the distorted input line current as sine wave approximately. The buck converter is used to feed the harmonic power absorbed by single PWM rectifier to the load. In Figure 1, the output voltage reference of auxiliary PWM rectifier is designed according to the input voltage of auxiliary PWM rectifier and the load current. The output voltage control loop of the auxiliary PWM rectifier is employed to maintain the output voltage as the output voltage reference, which helps the auxiliary PWM rectifier to inject the required triangle current accurately. When the harmonic power absorbed by single PWM rectifier changes, the output voltage of auxiliary PWM rectifier changes; then, the output signals of voltage simple and PI regulators change; the duty cycle of buck converter is adjusted correspondingly. It indicates that the harmonic power fed to the load is changed. Finally, output voltage of the auxiliary PWM rectifier is adjusted and maintained as the output voltage reference.

The injected triangle current, $i_{s}$, meets:

$$
i_{s}= \begin{cases}\frac{3 I_{d}}{m \pi} \cdot \omega t-\frac{I_{d}}{2 m} & 0 \leq \omega t \leq \frac{\pi}{3} \\ -\frac{3 I_{d}}{m \pi} \cdot \omega t+\frac{3 I_{d}}{2 m} & \frac{\pi}{3} \leq \omega t \leq \frac{2 \pi}{3} \\ \frac{3 I_{d}}{m \pi} \cdot \omega t-\frac{5 I_{d}}{2 m} & \frac{2 \pi}{3} \leq \omega t \leq \pi \\ -\frac{3 I_{d}}{m \pi} \cdot \omega t+\frac{7 I_{d}}{2 m} & \pi \leq \omega t \leq \frac{4 \pi}{3} \\ \frac{3 I_{d}}{m \pi} \cdot \omega t-\frac{9 I_{d}}{2 m} & \frac{4 \pi}{3} \leq \omega t \leq \frac{5 \pi}{3} \\ -\frac{3 I_{d}}{m \pi} \cdot \omega t+\frac{11 I_{d}}{2 m} & \frac{5 \pi}{3} \leq 2 \omega t \leq 2 \pi\end{cases}
$$

where $I_{d}$ is the average output current of the doublestar diode rectifier, and $m$ is the turn ratio between the secondary and primary windings of the specific IPR.

In Figure $1, L_{a 1}, L_{b 1}, L_{c 1}, L_{a 2}, L_{b 2}$, and $L_{c 2}$ are the equivalent leakage inductances of double-star transformer. The values of leakage inductance are assumed to be the same. That is:

$$
L_{a 1}=L_{b 1}=L_{c 1}=L_{a 2}=L_{b 2}=L_{c 2}=L_{S} .
$$

The double-star diode rectifier is supplied by a balanced three-phase voltage system:

$$
\left\{\begin{array}{l}
u_{a}=U_{m} \sin (\omega t) \\
u_{b}=U_{m} \sin (\omega t-2 \pi / 3) \\
u_{c}=U_{m} \sin (\omega t+2 \pi / 3)
\end{array}\right.
$$

where $U_{m}$ is the amplitude of input phase voltage. Assuming that the turn ratio of double-star trans- former is $1: k$, the output voltages of secondary-winding double-star transformer are:

$$
\begin{aligned}
& \left\{\begin{array}{l}
u_{a 1}=\frac{\sqrt{3} U_{m}}{k} \sin (\omega t+\pi / 6) \\
u_{b 1}=\frac{\sqrt{3} U_{m}}{k} \sin (\omega t-\pi / 2) \\
u_{c 1}=\frac{\sqrt{3} U_{m}}{k} \sin (\omega t+5 \pi / 6)
\end{array}\right. \\
& \left\{\begin{array}{l}
u_{a 2}=\frac{\sqrt{3} U_{m}}{k} \sin (\omega t-5 \pi / 6) \\
u_{b 2}=\frac{\sqrt{3} U_{m}}{k} \sin (\omega t+\pi / 2) \\
u_{c 2}=\frac{\sqrt{3} U_{m}}{k} \sin (\omega t-\pi / 6)
\end{array}\right.
\end{aligned}
$$

According to the Kirchhoff's current law and the Ampere-turns balance law of the transformer, the input current of the double-star rectifier is:

$$
\left\{\begin{array}{l}
i_{a}=\frac{1}{k}\left(i_{a 1}-i_{a 2}+i_{c 2}-i_{c 1}\right) \\
i_{b}=\frac{1}{k}\left(i_{b 1}-i_{b 2}+i_{a 2}-i_{a 1}\right) \\
i_{c}=\frac{1}{k}\left(i_{c 1}-i_{c 2}+i_{b 2}-i_{b 1}\right)
\end{array}\right.
$$

\subsection{Current commutation process of the double-star diode rectifier with AIPR}

When the triangle current, $i_{s}$, is injected into the additional secondary winding of the specific IPR, output currents of two three-phase half-wave rectifiers are:

$$
\begin{gathered}
i_{d 1}=\left\{\begin{array}{c}
\frac{I_{d}}{2}\left(\frac{6}{\pi} \cdot\left(\omega t-\frac{2 \pi}{3} p\right)\right) \\
\frac{2 \pi}{3} p \leq \omega t \leq \frac{2 \pi}{3}\left(p+\frac{1}{2}\right) \\
\frac{I_{d}}{2}\left(-\frac{6}{\pi} \cdot\left(\omega t-\frac{2 \pi}{3} p\right)+4\right) \\
\frac{2 \pi}{3}\left(p+\frac{1}{2}\right) \leq \omega t \leq \frac{2 \pi}{3}(p+1)
\end{array}\right. \\
i_{d 2}=\left\{\begin{array}{c}
I_{d}-\frac{I_{d}}{2}\left(\frac{6}{\pi} \cdot\left(\omega t-\frac{2 \pi}{3} p\right)\right) \\
\frac{2 \pi}{3} p \leq \omega t \leq \frac{2 \pi}{3}\left(p+\frac{1}{2}\right) \\
\frac{I_{d}}{2}\left(\frac{6}{\pi} \cdot\left(\omega t-\frac{2 \pi}{3} p\right)-2\right) \\
\frac{2 \pi}{3}\left(p+\frac{1}{2}\right) \leq \omega t \leq \frac{2 \pi}{3}(p+1)
\end{array}\right.
\end{gathered}
$$

where $p=0,1,2$. From Eqs. (7) and (8), it is noted that as a result of the modulation of the triangle current, $i_{s}$, output currents of two three-phase halfwave rectifiers are critical continuous, which make the current commutation process of the double-star diode rectifier with AIPR different from that of the conventional double-star diode rectifier. Figure 2 illustrates the main waveforms of the double-star diode rectifier with AIPR under large inductive load.

In Figure 2, due to the leakage inductance, $L_{s}$, the current commutation of double-star diode rectifier with AIPR has not been completed instantaneously; this affects the input line current. To analyze the 
(a)

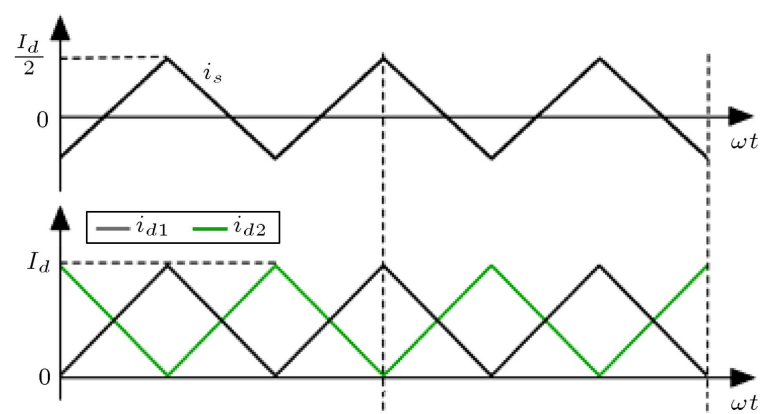

(c)

(d)

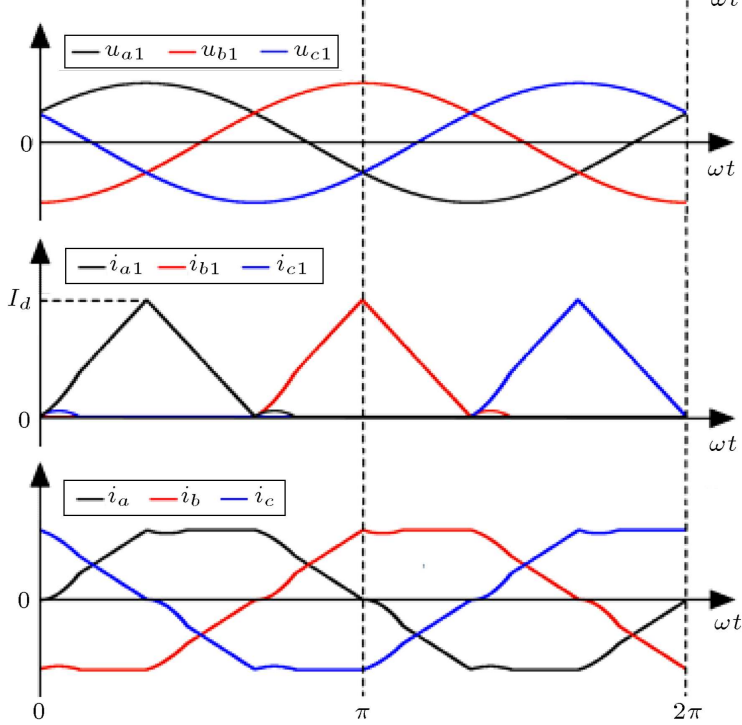

Figure 2. Main waveforms of the double-star diode rectifier with AIPR: (a) The injected triangle current, (b) output currents of two three-phase half-wave rectifiers, (c) input voltages of three-phase half-wave rectifiers, (d) input currents of three-phase half-wave rectifiers, and (e) input line currents of double-star diode rectifier with AIPR.

effects of the current commutation on the input current in details, we introduced the current commutation process of double-star diode rectifier with AIPR fistly. Figure 3 illustrates the main waveforms of the new current commutation from diode $D_{a 1}$ to diode $D_{b 1}$.

In Figure 3, when $\omega t<2 \pi / 3$, the input voltage $u_{a 1}$ is more than the input voltage $u_{b 1}$, the diode $D_{a 1}$ has been conducted and flown into the current $i_{d 1}$, current $i_{a 1}$ is equal to $i_{d 1}$, and current $i_{b 1}$ is zero. At $\omega t=2 \pi / 3$, the input voltage $u_{a 1}$ is equal to the input voltage $u_{b 1}$, the currents $i_{a 1}$ and $i_{d 1}$ decrease to zero exactly, diode $D_{a 1}$ is switched off, and $D_{b 1}$ is conducted automatically. When $\omega t>2 \pi / 3$, the input voltage $u_{a 1}$ is less than the input voltage $u_{b 1}$, the diode $D_{b 1}$ is conducted and flown into the current $i_{d 1}$, and current $i_{b 1}$ is equal to $i_{d 1}$. The current $i_{b 1}$ builds up from zero through diode $D_{b 1}$ and a voltage drop is produced by the current $i_{b 1}$ in $L_{b 1}$. Then, a forward-bias voltage appears across diode $D_{a 1}$ and diode $D_{a 1}$ is conducted again. Diode $D_{a 1}$ and diode $D_{b 1}$ are conducted simultaneously and current (a)

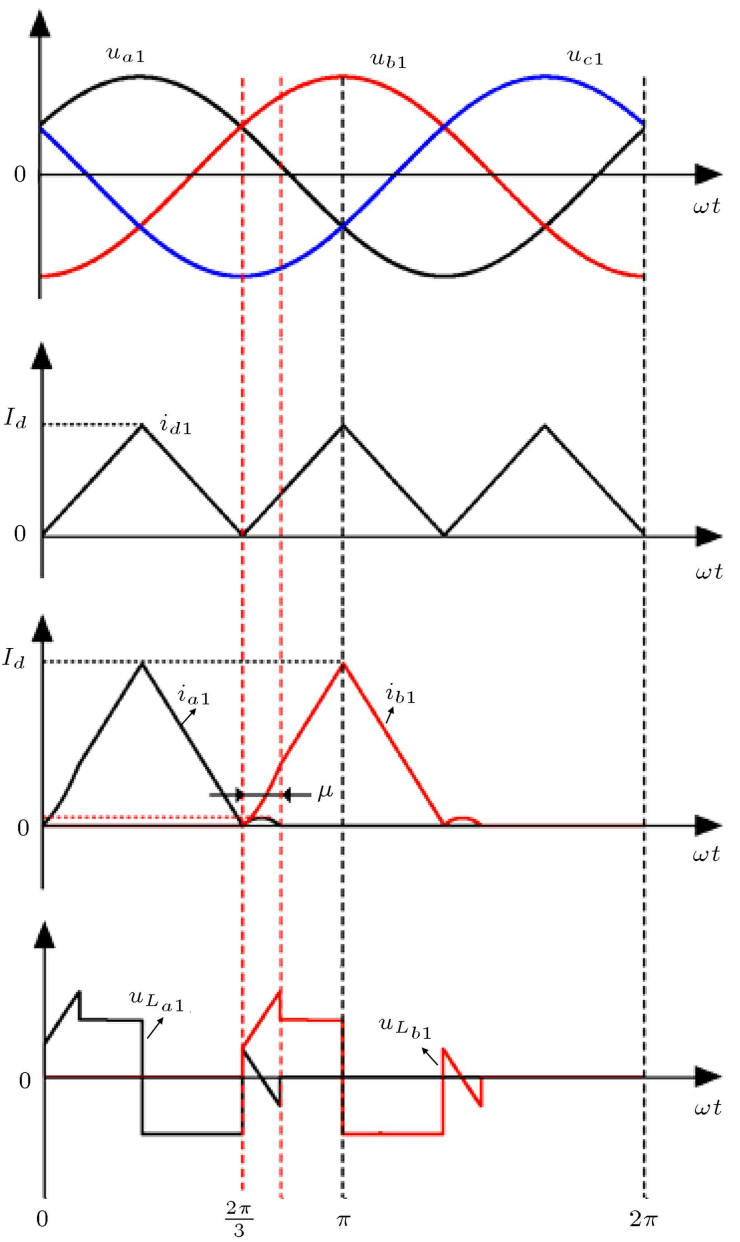

Figure 3. Main waveforms of new current commutation from diode $D_{a 1}$ to diode $D_{b 1}$ : (a) Input voltages of three-phase half-wave rectifier, (b) output currents of three-phase half-wave rectifier, (c) currents though diode $\mathrm{D}_{a 1}$ and diode $\mathrm{D}_{b 1}$, and (d) voltage across $L_{a 1}$ and $L_{b 1}$.

commutation process is produced. During the current commutation interval, diode $D_{a 1}$ and diode $D_{b 1}$ are conducted at the same time and the input voltages $u_{a 1}$ and $u_{b 1}$ are shortened through $L_{a 1}$ and $L_{b 1}$. The current commutation process from diode $D_{a 1}$ to diode $D_{b 1}$ is completed when current $i_{b 1}$ is equal to the output current $i_{d 1}$.

From the above analysis, it is noted that the time of commutation beginning is decided only by the input voltages $u_{a 1}, u_{b 1}$ and the output current $i_{d 1}$; thus, the voltage drops on diodes do not affect the time of commutation beginning.

In Figure 3, during the current commutation interval, the double-star diode rectifier with AIPR meets:

$$
\left\{\begin{array}{l}
u_{a 1}-L_{a 1} \frac{d i_{a 1}}{d t}=u_{b 1}-L_{b 1} \frac{d i_{b 1}}{d t} \\
i_{d 1}=i_{a 1}+i_{b 1}
\end{array}\right.
$$

From Eq. (9), it is noted that during the current 
commutation interval, the voltage drops on diodes do not affect the current wave.

Solving Eq. (9), the currents $i_{a 1}$ and $i_{b 1}$ are obtained as:

$$
\left\{\begin{array}{l}
i_{a 1}=\frac{3 I_{d}}{2 \pi}\left(\omega t-\frac{2 \pi}{3}\right)-\frac{\sqrt{6} U_{2}}{2 X_{s}}\left(1-\cos \left(\omega t-\frac{2 \pi}{3}\right)\right) \\
i_{b 1}=\frac{3 I_{d}}{2 \pi}\left(\omega t-\frac{2 \pi}{3}\right)+\frac{\sqrt{6} U_{2}}{2 X_{s}}\left(1-\cos \left(\omega t-\frac{2 \pi}{3}\right)\right)
\end{array}\right.
$$

where $U_{2}$ is the RMS value of input phase voltage of three-phase half-wave rectifier and $X_{s}=\omega L_{s}$ is the leakage inductive reactance of transformer.

Considering that current $i_{b 1}$ changes from 0 to $i_{d 1}$ in the current commutation interval, the relation between the overlap angle $\mu$ and the circuit parameters can be obtained:

$$
3 \mu X_{B} I_{d}=\sqrt{6} U_{2} \pi(1-\cos \mu) .
$$

In Eq. (11), the overlap angle $\mu$ is proportional to the leakage inductance of transformer and dc output current, but it is inversely proportional to the output voltage of the double transformer.

\subsection{Effects of the leakage inductance on the input current}

According to Eq. (6) and Figure 1, in order to establish the expression between the leakage inductive of transformer and input current, the expression of output currents of double-star transformer should be calculated firstly.

From Eqs. (7) and (10), by combining the phase relation between the currents $i_{a 1}$ and $i_{b 1}$, the output current $i_{a 1}$ of double-star transformer can be obtained as:

$$
i_{a 1}=\left\{\begin{array}{lc}
\frac{3 I_{d}}{2 \pi} \omega t+\frac{\sqrt{6} U_{2}}{2 X_{s}}(1-\cos (\omega t)) & 0 \leq \omega t \leq \mu \\
\frac{3 I_{d}}{\pi} \omega t & \mu \leq \omega t \leq \frac{\pi}{3} \\
-\frac{3 I_{d}}{\pi} \omega t+2 I_{d} & \frac{\pi}{3} \leq \omega t \leq \frac{2 \pi}{3} \\
\frac{3 I_{d}}{2 \pi}\left(\omega t-\frac{2 \pi}{3}\right)-\frac{\sqrt{6} U_{2}}{2 X_{s}}\left(1-\cos \left(\omega t-\frac{2 \pi}{3}\right)\right) & \frac{2 \pi}{3} \leq \omega t \leq \frac{2 \pi}{3}+\mu \\
0 & \frac{2 \pi}{3}+\mu \leq \omega t \leq 2 \pi
\end{array}\right.
$$

Since the principle of six times current commutation is identical in one-line period, according to the phase relation among output currents of double-star transformer, which is shown in Figure 4, the output currents of double-star transformer $i_{a 2}, i_{c 1}$, and $i_{c 2}$ are calculated as:

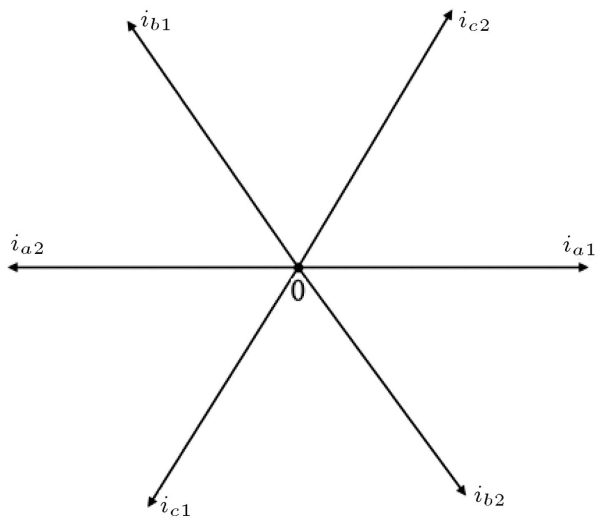

Figure 4. The phase relation among output currents of double-star transformer.

$$
\begin{aligned}
& i_{a 2}=\left\{\begin{array}{lc}
0 & 0 \leq \omega t \leq \pi \\
\frac{3 I_{d}}{2 \pi}(\omega t-\pi)+\frac{\sqrt{6} U_{2}}{2 X_{s}}(1-\cos (\omega t-\pi)) & \pi \leq \omega t \leq \pi+\mu \\
\frac{3 I_{d}}{\pi}(\omega t-\pi) & \pi+\mu \leq \omega t \leq \frac{4 \pi}{3} \\
-\frac{3 I_{d}}{\pi}(\omega t-\pi)+2 I_{d} & \frac{4 \pi}{3} \leq \omega t \leq \frac{5 \pi}{3} \\
\frac{3 I_{d}}{2 \pi}\left(\omega t-\frac{5 \pi}{3}\right)-\frac{\sqrt{6} U_{2}}{2 X_{s}} & \left(1-\cos \left(\omega t-\frac{5 \pi}{3}\right)\right) \\
& \frac{5 \pi}{3} \leq \omega t \leq \frac{5 \pi}{3}+\mu \\
0 & \frac{5 \pi}{3}+\mu \leq \omega t \leq 2 \pi
\end{array}\right. \\
& i_{c 1}=\left\{\begin{array}{lc}
\frac{3 I_{d}}{2 \pi}(\omega t)-\frac{\sqrt{6} U_{2}}{2 X_{s}}(1-\cos (\omega t)) & 0 \leq \omega t \leq \mu \\
0 & \mu \leq \omega t \leq \frac{4 \pi}{3} \\
\frac{3 I_{d}}{2 \pi}\left(\omega t-\frac{4 \pi}{3}\right)+\frac{\sqrt{6} U_{2}}{2 X_{s}} & \left(1-\cos \left(\omega t-\frac{4 \pi}{3}\right)\right) \\
\frac{4 \pi}{3} \leq \omega t \leq \frac{4 \pi}{3}+\mu \\
\frac{3 I_{d}}{\pi}\left(\omega t-\frac{4 \pi}{3}\right) & \frac{4 \pi}{3}+\mu \leq \omega t \leq \frac{5 \pi}{3} \\
-\frac{3 I_{d}}{\pi}\left(\omega t-\frac{4 \pi}{3}\right)+2 I_{d} & \frac{5 \pi}{3} \leq \omega t \leq 2 \pi
\end{array}\right. \\
& i_{c 2}=\left\{\begin{array}{lc}
0 & 0 \leq \omega t \leq \frac{\pi}{3} \\
\frac{3 I_{d}}{2 \pi}\left(\omega t-\frac{\pi}{3}\right)+\frac{\sqrt{6} U_{2}}{2 X_{s}}\left(1-\cos \left(\omega t-\frac{\pi}{3}\right)\right) \\
\frac{\pi}{3} \leq \omega t \leq \frac{\pi}{3}+\mu \\
\frac{3 I_{d}}{\pi}\left(\omega t-\frac{\pi}{3}\right) & \frac{\pi}{3}+\mu \leq \omega t \leq \frac{2 \pi}{3} \\
-\frac{3 I_{d}}{\pi}\left(\omega t-\frac{\pi}{3}\right)+2 I_{d} & \frac{2 \pi}{3} \leq \omega t \leq \pi \\
\frac{3 I_{d}}{2 \pi}(\omega t-\pi)-\frac{\sqrt{6} U_{2}}{2 X_{s}}(1- & \cos (\omega t-\pi)) \\
& \pi \leq \omega t \leq \pi+\mu \\
0 & \pi+\mu \leq \omega t \leq 2 \pi
\end{array}\right.
\end{aligned}
$$


Substituting Eqs. (12)-(15) into Eq. (6), the input current, $i_{a}$, is:

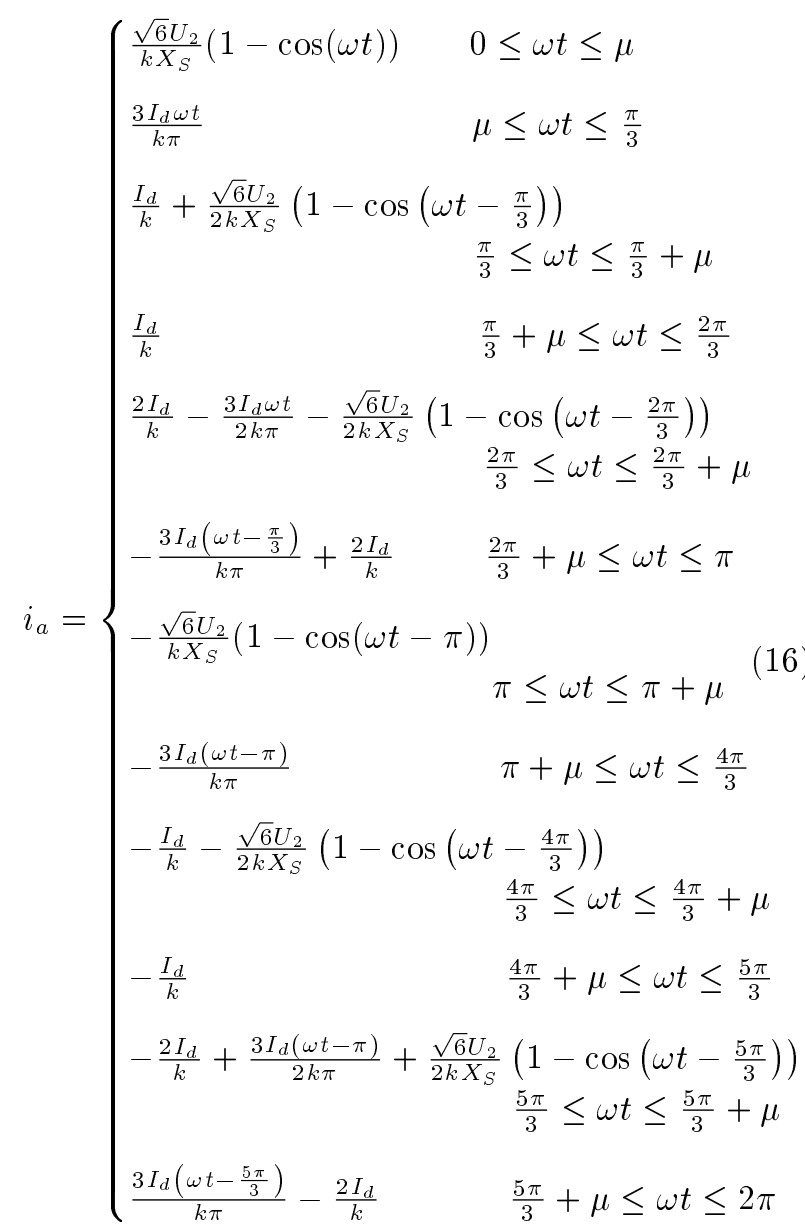

The Root-Mean-Square (RMS) value and the fundamental harmonic of the input current $i_{a}$ are calculated as shown in Box I.

$\phi_{1}$ is the input current lag angle, and it meets Relation (20) as shown in Box II. To establish the relation between the input current and the leakage inductances of transformer in a general method, we define the leakage inductance factor $K_{L s}$ as:

$$
K_{L s}=\frac{X_{s}}{\frac{\sqrt{6} U_{2}}{2 I_{d}}}
$$

Based on the relation between the overlap angle and the circuit parameters shown in Eq. (11), the leakage inductance factor, $K_{L s}$, is equal to 1 when the overlap angle is equal to the maximum value $60^{\circ}$.

According to the definition of the input current THD, combing Eqs. (19), (20), and (11), the input current THD of double-star diode rectifier with AIPR has been calculated. Figure 5 illustrates the input current THDs of the conventional double-star diode rectifier and the double-star diode rectifier with AIPR when the leakage inductance factor, $K_{L s}$, changes from 0 to 1 .

In Figure 5, it is clear that the effects of leakage inductance on the input current THDs of conventional double-star diode rectifier and double-star diode rectifier with AIPR are different. With the increase in

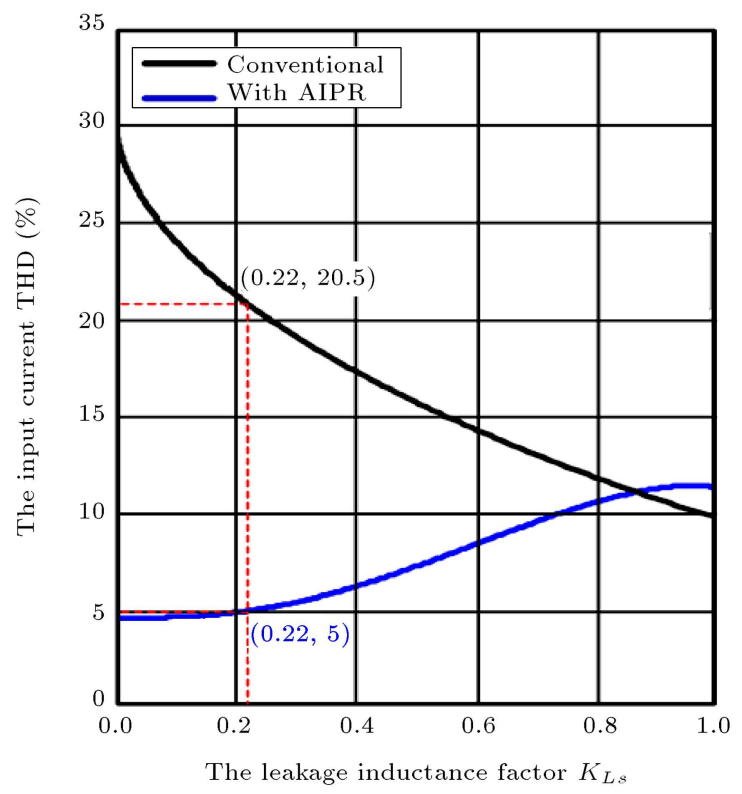

Figure 5. Relation between the input current THD and the leakage inductance factor $K_{L s}$.

$$
\begin{aligned}
& I_{a \mathrm{RMS}}=\frac{\sqrt{\left.162 \mu^{3} \cos \mu(2-\cos \mu)+243 \mu^{2} \sin \mu(\cos \mu-4)+20 \pi^{3}(1-\cos \mu)^{2}+576 \mu\right)}}{6 \pi^{\frac{3}{2}}(1-\cos \mu)}, \\
& I_{a .1}=\sqrt{2} I_{a 1 \mathrm{RMS}} \sin \left(\omega t+\phi_{1}\right),
\end{aligned}
$$

where:

$$
I_{a 1 \mathrm{RMS}}=\frac{3 \sqrt{18\left(2+\mu \cos \mu \sin \mu-\mu^{2}-4 \cos \mu+2 \cos ^{2} \mu\right)^{2}+2(1-\cos \mu)^{2}(6 \sin \mu-3 \mu-3 \mu \cos \mu-4 \sqrt{3})^{2}}}{4 \pi^{2}(1-\cos \mu)} .
$$




$$
\phi_{1}=\arctan \left(\frac{6 \cos \mu \sin \mu-3 \mu \cos ^{2} \mu-4 \sqrt{3} \cos \mu-6 \sin \mu+3 \mu+4 \sqrt{3}}{6+3 \mu \cos \mu \sin \mu-3 \mu^{2}-12 \cos \mu+6 \cos ^{2} \mu}\right)
$$

\section{Box II}

leakage inductance factor $K_{L s}$, the input current THD of conventional double-star diode rectifier decreases, but it increases in the double-star diode rectifier with AIPR. It is noted that the input current THDs of conventional double-star diode rectifier and double-star diode rectifier with AIPR are the same when leakage inductance factor, $K_{L s}$, equals 0.83 . It indicates that the double-star diode rectifier with AIPR cannot reduce the input current harmonics when the leakage inductance factor $K_{L s}$ is more than 0.83 .

To ensure that the input current THD of doublestar diode rectifier with AIPR meets the standards of IEEE-519 and IEC 1000-3, it should be less than $5 \%$. In Figure 5, the leakage inductance factor, $K_{L s}$, is equal to 0.22 when the input current THD is $5 \%$; thus, the design of double-star transformer should make the leakage inductance factor, $K_{L s}$, less than 0.22 .

Combing Eqs. (20) and (11), the relation between the input current lag angle, $\phi_{1}$, and the leakage inductance factor, $K_{L s}$, is obtained. Figure 6 shows the input current lag angles of the conventional double-star diode rectifier and the double-star diode rectifier with AIPR when the leakage inductance factor $K_{L s}$ changes from 0 to 1 .

In Figure 6, compared with the conventional double-star diode rectifier, the input current lag angle $\phi_{1}$ produced by the leakage inductance of transformer is reduced effectively by the AIPR. It indicates that the double-star diode rectifier with AIPR has the smaller input current lag angle, $\phi_{1}$, and the higher displacement factor. With the increase in leakage inductance factor $K_{L s}$, the input current lag angle,

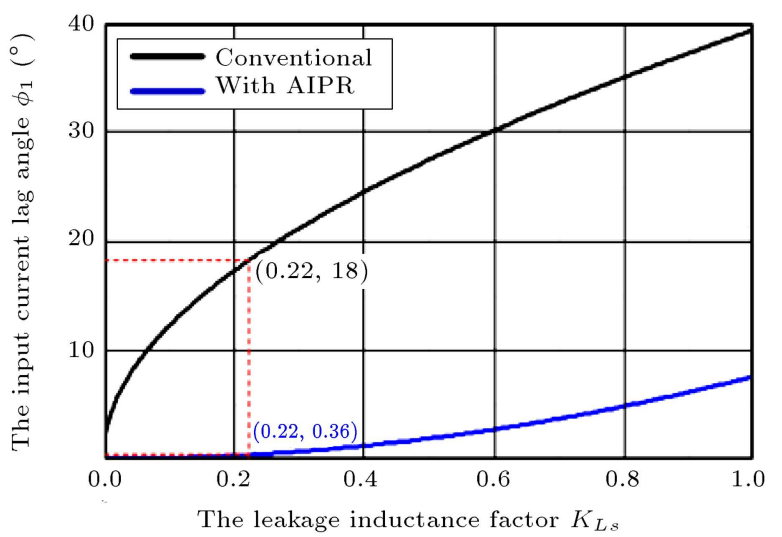

Figure 6. Relation between the input current lag angle, $\phi_{1}$, and the leakage inductance factor, $K_{L s}$.

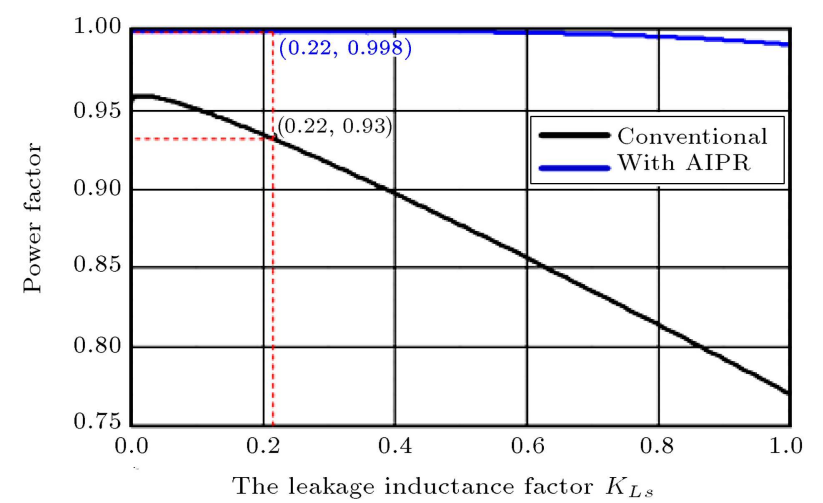

Figure 7. Relation between the power factor and the leakage inductance factor, $K_{L s}$.

$\phi_{1}$, of double-star diode rectifier with AIPR increases. When the leakage inductance factor, $K_{L s}$, equals 0.22 , the input current lag angle, $\phi_{1}$, is only $0.36^{\circ}$.

Figure 7 illustrates the power factors of the conventional double-star diode rectifier and the doublestar diode rectifier with AIPR when the leakage inductance factor, $K_{L s}$, changes from 0 to 1 .

In Figure 7 , with increase in leakage inductance factor $K_{L s}$, the power factors of conventional doublestar diode rectifier and double-star diode rectifier with AIPR decrease. Compared with the conventional double-star diode rectifier, the double-star diode rectifier with AIPR has high power factor. The power factor of the double-star diode rectifier with AIPR is more than 0.985 when leakage inductance factor, $K_{L s}$, changes from 0 to 1 .

\section{Simulation results}

In order to demonstrate the effects of leakage inductance on its input current, the double-star diode rectifier with AIPR is simulated in Saber software. The circuit parameters of double-star rectifier with AIPR for simulation are given in Table 1 . The simulation results are shown in Figures 8-12.

Figure 8 illustrates the input voltages of the three-phase half-wave rectifier, the output current of the three-phase half-wave rectifier, and the currents through diode $D_{a 1}$ and diode $D_{b 1}$ when the leakage inductance $L_{s}$ is 0 and $1.18 \mathrm{mH}$ (corresponding leakage inductance factor $K_{L s}=0.8$ ), respectively.

In Figure 8, it is clear that due to the leakage inductance $L_{s}$, the current commutation of double- 
Table 1. Parameters of double-star diode rectifier with AIPR for simulation.

\begin{tabular}{|c|c|c|}
\hline Symble & Description & Value \\
\hline$\sqrt{3} U_{m}$ & Line-to-line utility voltage in RMS & $380 \mathrm{~V}$ \\
\hline$f$ & Frequency of utility voltage & $50 \mathrm{~Hz}$ \\
\hline$k$ & Turns ratio of the primary and the secondary windings of the doubel-star transformer T1 & $10: 1$ \\
\hline$V_{D}$ & Voltage drop on diode & $0.7 \mathrm{~V}$ \\
\hline$L$ & Load filtering inductance & $15 \mathrm{mH}$ \\
\hline$I_{d}$ & Output current & $100 \mathrm{~A}$ \\
\hline$f_{c}$ & Current injection circuit switching frequency & $40 \mathrm{kHz}$ \\
\hline$L_{s}$ & Current injection circuit input filtering inductance & $1200 \mu \mathrm{H}$ \\
\hline$C_{1}$ & Current injection circuit output filtering capacitance & $1470 \mu \mathrm{F}$ \\
\hline$f_{b}$ & Buck converter switching frequency & $40 \mathrm{kHz}$ \\
\hline$L_{f}$ & Buck converter output filtering inductance & $10 \mathrm{mH}$ \\
\hline$m$ & Turns ratio of the primary and secondary windings of the AIPR & $1: 2$ \\
\hline
\end{tabular}

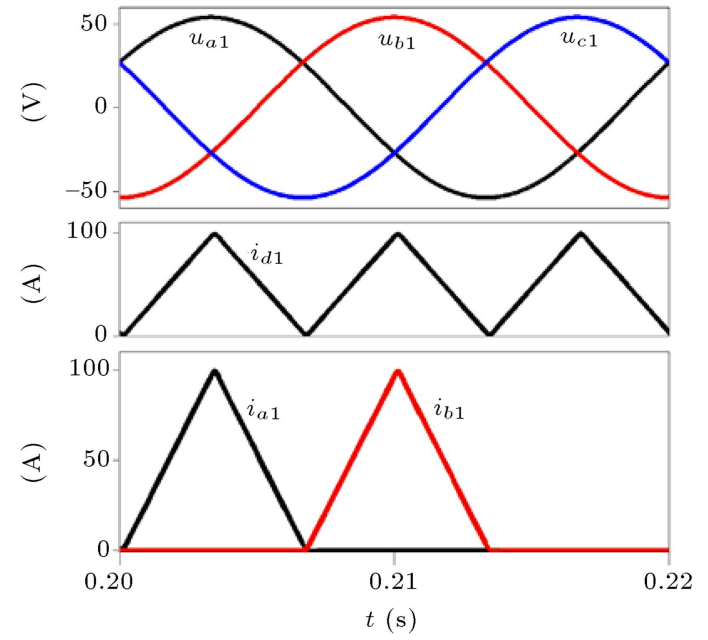

(a)

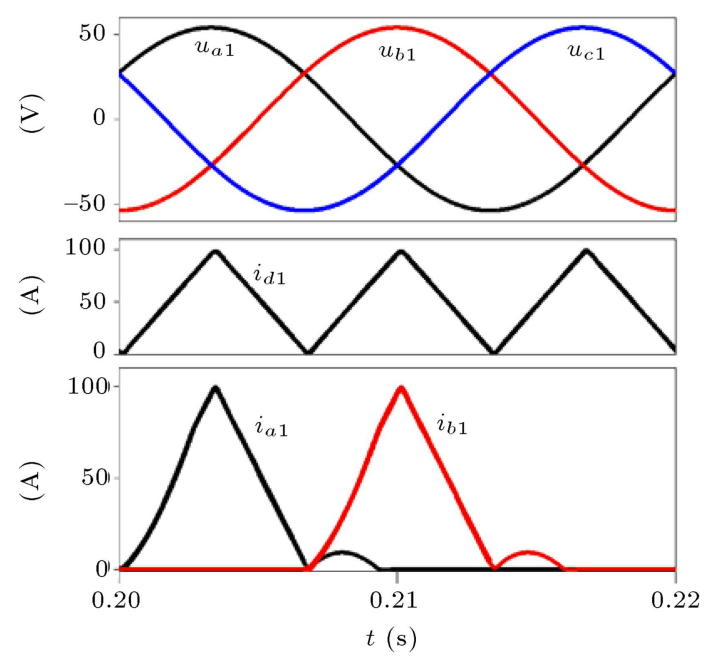

(b)

Figure 8. The input voltages of the three-phase half-wave rectifier, the output current of the three-phase half-wave rectifier, and the currents through diode $D_{a 1}$ and diode $D_{b 1}$ : (a) The leakage inductance $L_{s}=0$, and (b) the leakage inductance $L_{s}=1.18 \mathrm{mH}$.
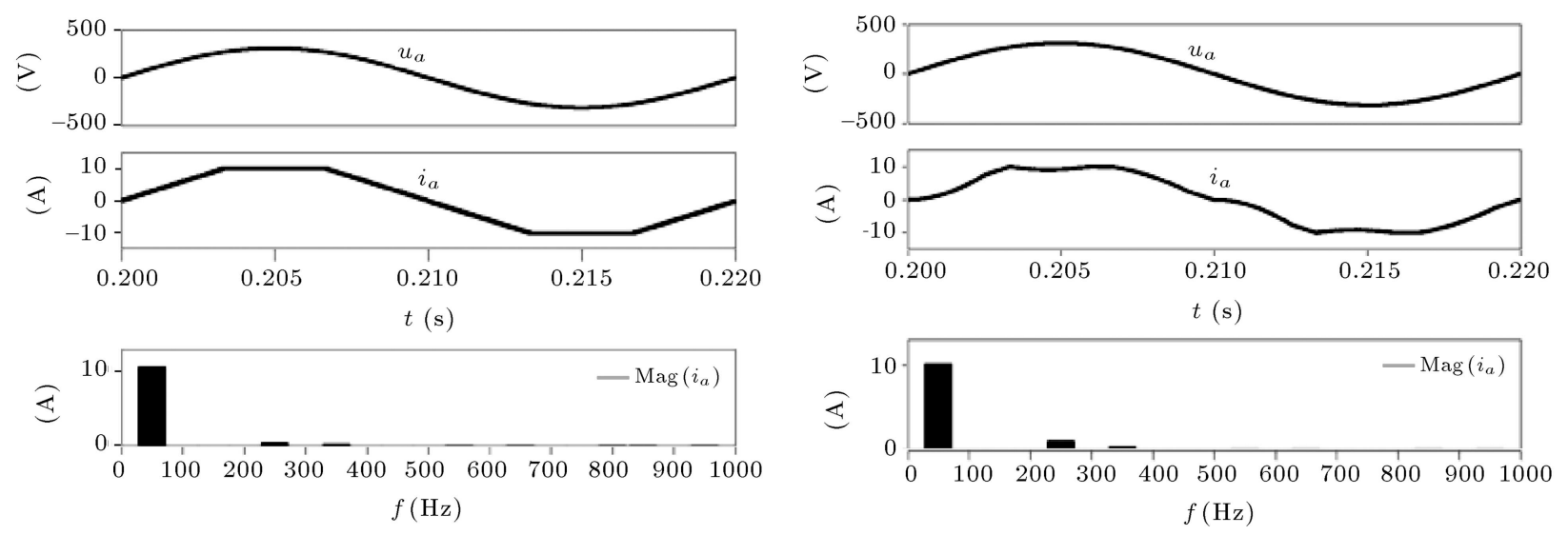

(a)

(b)

Figure 9. The input voltage, the input current, and the spectrum of input current of double-star diode rectifier with AIPR: (a) The leakage inductance $L_{s}=0$, and (b) the leakage inductance $L_{s}=1.18 \mathrm{mH}$. 


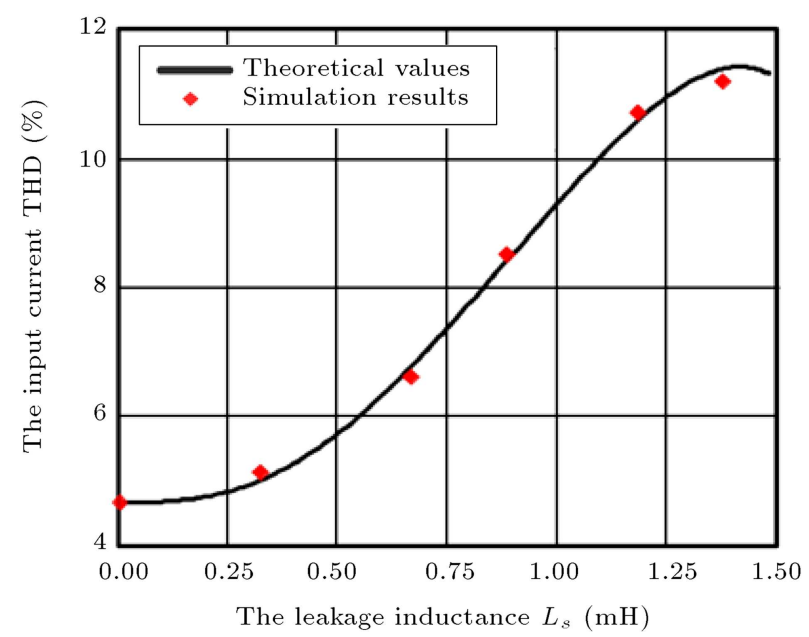

Figure 10. The input current THD of double-star diode rectifier with AIPR under different leakage inductance conditions.

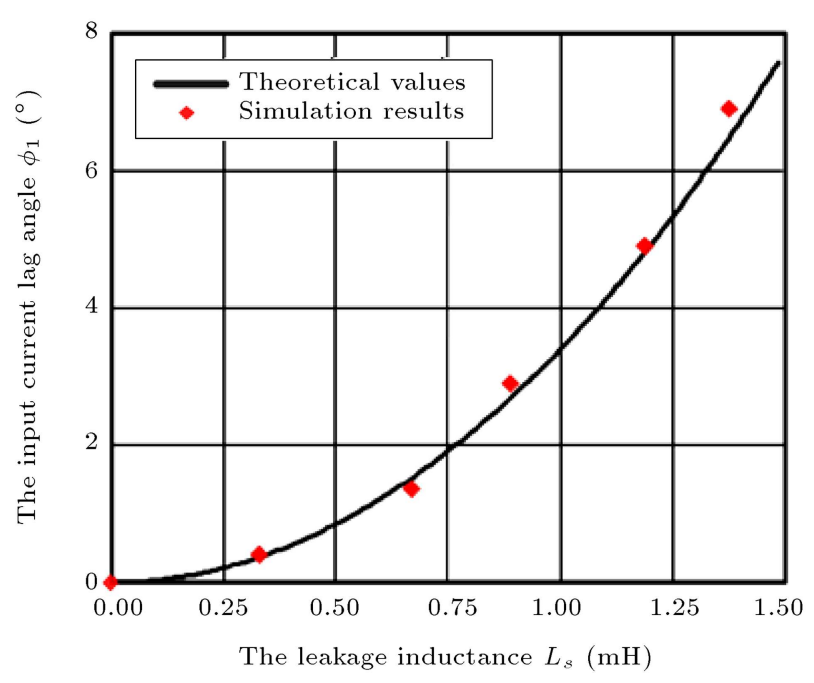

Figure 11. The input current lag angle $\phi_{1}$ of double-star diode rectifier with AIPR under different leakage inductance conditions.

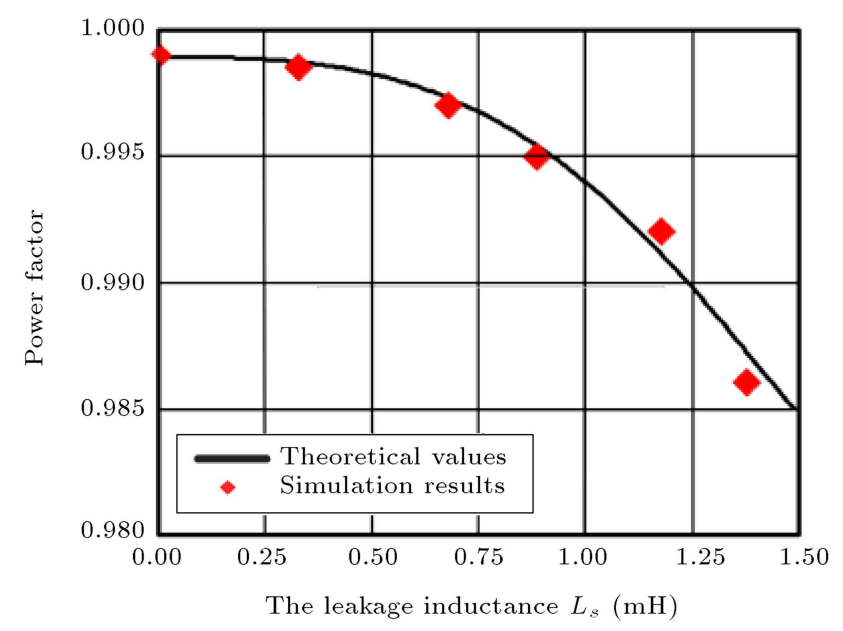

Figure 12. The power factor of double-star diode rectifier with AIPR under different leakage inductance conditions. star diode rectifier with AIPR cannot be completed instantaneously; the current commutation from diode $D_{a 1}$ to diode $D_{b 1}$ takes place under new current commutation mode.

Figure 9 illustrates the input voltage, the input current, and the spectrum of input current of doublestar diode rectifier with AIPR when the leakage inductance $L_{s}$ is 0 and $1.18 \mathrm{mH}$ (corresponding leakage inductance factor $\left.K_{L s}=0.8\right)$, respectively.

Comparing Figure 9(a) and Figure 9(b), it is obvious that the leakage inductance $L_{s}$ leads to increase in the input current harmonics. The input current THD increases from $4.6 \%$ to $10.5 \%$, which is consistent with the theoretical analysis. Due to the leakage inductance $L_{s}$, the input current lag angle $\phi_{1}$ also increases from 0 to $2.5^{\circ}$.

According to the definition of the leakage inductance factor $K_{L s}$, under the simulation parameters shown in Table 1, the relation between the leakage inductance, $L_{s}$, and the leakage inductance factor, $K_{L s}$, is obtained as:

$$
L_{s}=1.49 K_{L s} \quad(\mathrm{mH}) \text {. }
$$

From Eq. (22), the leakage inductance, $L_{s}$, changes from 0 to $1.49 \mathrm{mH}$ when the leakage inductance factor, $K_{L s}$, changes from 0 to 1 .

To correspond to Figure 5, Figure 10 illustrates the input current THD of double-star diode rectifier with AIPR under different leakage inductance conditions.

In Figure 10, it is clear that with increase in leakage inductance $L_{s}$, the input current THD increases. The simulation results are consistent with the theoretical analysis in Figure 5. When the leakage inductance $L_{s}$ is less than $327 \mathrm{uH}$ (corresponding leakage inductance factor $\left.K_{L s}=0.22\right)$, the input current THD is less than $5 \%$.

To correspond to Figure 6, Figure 11 shows the input current lag angle $\phi_{1}$ of double-star diode rectifier with AIPR under different leakage inductance conditions.

In Figure 11, it can be seen that the leakage inductance, $L_{s}$, leads to increase in the input current lag angle $\phi_{1}$. It indicates that the leakage inductance $L_{s}$ reduces the displacement factor of double-star rectifier with AIPR.

To correspond to Figure 7, Figure 12 shows the power factor of double-star diode rectifier with AIPR under different leakage inductance conditions.

In Figure 12, with increase in leakage inductance $L_{s}$, the power factor of double-star diode rectifier with AIPR decreases slightly; it is not less than 0.985 when the leakage inductance $L_{s}$ changes from 0 to $1.49 \mathrm{mH}$. Compared with conventional double-star diode rectifier, the double-star diode rectifier with AIPR operates under almost unity power factor condition. 


\section{Conclusion}

In this paper, the effects of leakage inductance of transformer on the input line current of the doublestar rectifier with AIPR are analyzed in depth. The theoretical analysis results indicate that the leakage inductance of transformer leads to increase in the input current harmonics of the double-star rectifier with AIPR, and the input current THD is greater than $5 \%$ when the leakage inductance factor $K_{L s}$ is more than 0.22 . The leakage inductance of transformer also increases the input current lag angle of the doublestar rectifier with AIPR. It indicates that leakage inductance of transformer decreases the displacement factor. In order to ensure that the double-star diode rectifier with AIPR meets the requirements of the harmonics limitation standard and operates under almost unity displacement factor and power factor, the leakage inductance factor $K_{L s}$ of the double-star transformer should be less than 0.22 .

Owing to the essence of the diode rectifiers, the same active current injection reduction method is used. The analysis method for the effects of leakage inductance of transformer on the input current in this paper can be extended to analyze other diode rectifiers with active current injection circuit, such as 12-pulse diode rectifier with active current injection circuit.

\section{References}

1. Siebert, A., Troedson, A. and Ebner, S. "Ac to dc power conversion now and in the future", IEEE Transactions on Industry Applications, 14(1), pp. 1876-1884 (2013).

2. Singh, B., Gairola, S., Singh, B.N., Chandra, A. and Al-Haddad, K. "Multipulse AC-DC converters for improving power quality: a review", IEEE Transactions on Power Electronics, 23(1), pp. 260-281 (2008).

3. IEEE Guide for Recommended Control and Reactive Compensation of Static Power Converters, IEEE Standard 519 (1992).

4. Limitation of Emission of Harmonic Currents in LowVoltage Power Supply Systems for Equipment With Rated Current Greater Than 16 A, IEC 61000-3-4 (1998).

5. Swamy, M., Kume, T.J. and Takada, N. "A hybrid 18pulse rectification scheme for diode front-end rectifiers with large DC bus capacitor", IEEE Transactions on Industry Applications, 46(6), pp. 2484-2494 (2010).

6. Choi, S. "A three-phase unity-power-factor diode rectifier with active input current shaping", IEEE Transactions on Industrial Electronics, 52(6), pp. 1711-1714 (2005).

7. Maswood, AI. and Liu, FR. "A novel unity power factor input stage for AC drive applications", IEEE Transactions on Power Electronics, 20(4), pp. 839-846 (2005).
8. Tangtheerajaroonwong, W., Hatada, T. and Wada, K. "Design and performance of a transformerless shunt hybrid filter integrated into a three-phase diode rectifier", IEEE Transactions on Power Electronics, 22(5), pp. 1882-1889 (2007).

9. Saidi, S., Abbassi, R. and Chebbi, S. "Virtual flux based direct power control of shunt active filter", Scientia Iranica. Transaction D, Computer Science \& Engineering and Electrical Engineering, 21(6), pp. 99109 (2014).

10. Le Roux, A.D., Mouton, H. du T. and Akagi, H. "DFT-based repetitive control of a series active filter integrated with a 12-pulse diode rectifier", IEEE Transactions on Power Electronics, 24(6), pp. 15151521 (2009).

11. Akagi, H. and Isozaki, K. "A hybrid active filter for a three-phase 12-pulse diode rectifier used as the front end of a medium-voltage motor drive", IEEE Transactions on Power Electronics, 27(1), pp. 69-77 (2012).

12. Villablanca, M.E., Nadal, J.I. and Bravo, M.A. "A 12pulse AC-DC rectifier with high-quality input/output waveforms", IEEE Transactions on Power Electronics, 22(5), pp. 1875-1881 (2007).

13. Fukuda, S., Ohta, M. and Iwaji, Y. "An auxiliarysupply-assisted harmonic reduction scheme for 12pulse diode rectifiers", IEEE Transactions on Power Electronics, 23(3), pp. 1270-1277 (2008).

14. Singh, B., Bhuvaneswari, G., Garg, V. and Gairola, S. "Harmonic mitigation in AC-DC converters for vector controlled induction motor drives", IEEE Transactions on Energy Conversion, 22(3), pp. 637-646 (2007).

15. Mino, K., Gong, G. and Kolar, J.W. "Novel hybrid 12pulse boost-type rectifier with controlled output voltage", IEEE Transactions on Aerospace and Electronic System, 41(3), pp. 1008-1018 (2005).

16. Biela, J., Hassler, D. and Schoenberger, J. "Closedloop sinusoidal input-current shaping of 12-pulse autotransformer rectifier unit with impressed output voltage", IEEE Transactions on Power Electronics, 26(1), pp. 249-259 (2011).

17. Araujo-Vargas, I., Forsyth, A.J. and Chivite-Zabalza, F.J. "High perfor-mance multi-pulse rectifier with single transistor active injection", IEEE Transactions on Power Electronics, 23(3), pp. 1299-1308 (2008).

18. Lee, BS., Hahn, J. and Enjeti, PN. "A robust threephase active power-factor-correction and harmonic reduction scheme for high power", IEEE Transactions on Industry Electronics, 46(3), pp. 483-493 (1999).

19. Choi, S., Enjeti, P.N., Lee, H.H. and Pitel, I.J. "A new active inter-phase reactor for 12-pulse rectifiers provides clean power utility interface", IEEE Transactions on Industry Applications, 32(6), pp. 1304-1311 (1996).

20. Bai, S. and Lukic, S.M. "New method to achieve AC harmonic elimination and energy storage integration 
for 12-pulse diode rectifiers", IEEE Transactions on Industrial Electronics, 60(7), pp. 2547-2554 (2013).

21. Young, C.M., Chen, M.H. and Lai, C.H. "A novel active interphase transformer scheme to achieve threephase line current balance for 24-Pulse converter", IEEE Transactions on Power Electronics, 27(4), pp. 1719-1731 (2012).

22. Wang, J., Yang, S., Yang, W. and Li, Y. "A low harmonic double star rectifier with current injection at DC side", International Power Electronics and Application and Exposition Conference, Shanghai, China, pp. 909913 (2014).

23. Meng, F., Yang, S., Yang, W. and Gao, L. "Active harmonic reduction for 12-pulse diode bridge rectifier at DC side with two-stage auxiliary circuit", IEEE Transactions on Industrial Information, 11(1), pp. 6473 (2015).

24. Young, C.M., Wu, S.F. and Yeh, W.S. "A DCside current injection method for improving AC line condition applied in the 18-pulse converter system", IEEE Transactions on Power Electronics, 29(1), pp. 99-109 (2014).

25. Mao, L., Ren, X., Ruan, X. and Jiang, L. "Research of the current-injection-based P-type 12-pulse ATRU", International Power Electronics and Motion Control Conference, Harbin, China, pp. 41-46 (2012).

26. Wang, M. and Zhang, F. "12-pulse auto-transformer rectifier with harmonic current injection for non-grid- connected wind power applications", World Non-GridConnected Wind Power and Energy Conference, Nanjing, China, pp. 226-230 (2009).

\section{Biographies}

Jingfang Wang was born in Hebei, China, in 1984. He received the BS degree in Automation from Yanshan University, Qinhuangdao, China, in 2008 and the MS degree in Electrical Engineering from the Harbin Engineering University, Harbin, China, in 2012. Since 2012, he has been working towards the PhD degree in Electrical Engineering at the Harbin Institute of Technology, Harbin, China.

His research interests include high power converters and harmonics compensation.

Shiyan Yang was born in Heilongjiang, China, in 1962. He received the BS and MS degrees in Electrical Engineering and the $\mathrm{PhD}$ degree in Welding Engineering from the Harbin Institute of Technology, Harbin, China, in 1984, 1989, and 1998, respectively.

He is currently a professor and supervisor of Doctoral Candidates at the Harbin Institute of Technology. He has published over 60 papers. His research interests include high-power special type power supply and its application, energy storage system and its equilibrium, and fundamental theory of finity power supply drive and key commonsense problem. 